\title{
Clinical Phenotypes of Behavioral Variant Frontotemporal Dementia by Age at Onset
}

Jay L.P. Fieldhouse ${ }^{\mathrm{a}, *}$, Flora T. Gossink ${ }^{\mathrm{b}, \mathrm{c}}$, Thomas C. Feenstra ${ }^{\mathrm{d}}$, Sterre C.M. de Boer ${ }^{\mathrm{a}}$, Afina W. Lemstra ${ }^{\mathrm{a}}$, Niels D. Prins ${ }^{\mathrm{a}, \mathrm{e}}$, Femke Bouwman ${ }^{\mathrm{a}}$, Ted Koene ${ }^{\mathrm{a}}$, Hanneke F.M. Rhodius-Meester ${ }^{\mathrm{a}, \mathrm{f}}$, Freek Gillissen ${ }^{\mathrm{a}}$, Charlotte E. Teunissen ${ }^{\mathrm{a}, \mathrm{g}}$, Wiesje M. van der Flier ${ }^{\mathrm{a}}$, Philip Scheltens ${ }^{\mathrm{a}}$, Annemieke Dols ${ }^{\mathrm{b}}$, Everard G.B. Vijverberg ${ }^{\mathrm{a}, \mathrm{e}}$ and Yolande A.L. Pijnenburg ${ }^{\mathrm{a}}$ ${ }^{a}$ Alzheimer Center Amsterdam, Department of Neurology, Amsterdam Neuroscience, Vrije Universiteit Amsterdam, Amsterdam UMC, Amsterdam, The Netherlands

${ }^{\mathrm{b}}$ GGZ inGeest, Department of Old Age Psychiatry, Vrije Universiteit Amsterdam, Amsterdam UMC, Amsterdam, The Netherlands

${ }^{\mathrm{c}}$ Reinier van Arkel, Geriatric and Hospital Psychiatric Centre (COZ), Jeroen Bosch Hospital, Den Bosch, The Netherlands

${ }^{\mathrm{d}}$ GGZ Centraal, Department of Psychiatry, Amersfoort, The Netherlands

${ }^{\mathrm{e}}$ Brain Research Center, Amsterdam, The Netherlands

${ }_{\mathrm{f}}^{\mathrm{f}}$ Department of Internal medicine, Geriatric Medicine section, Vrije Universiteit Amsterdam, Amsterdam UMC, Amsterdam, The Netherlands

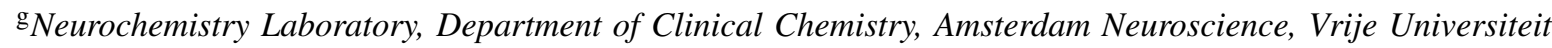
Amsterdam, Amsterdam UMC, Amsterdam, The Netherlands

Accepted 17 April 2021

Pre-press 19 May 2021

\begin{abstract}
.
Background: Behavioral variant frontotemporal dementia (bvFTD) is generally considered a young-onset dementia, although age at onset is highly variable. While several studies indicate clinical differences regarding age at onset, no biomarker validated cohort studies with updated clinical criteria have been performed.

Objective: We aimed to examine behavior, cognition, and mortality over the full age spectrum in a cohort of bvFTD patients with neuroimaging, genetic, or histopathological confirmation and exclusion of positive Alzheimer's disease biomarkers or severe cerebrovascular damage.

Methods: In total, 315 patients with a clinical diagnosis of probable or definite bvFTD were included from the Amsterdam Dementia Cohort and grouped into quartiles by age-at-diagnosis. Neuropsychiatric symptoms and cognitive functioning were assessed with the neuropsychiatric inventory, the geriatric depression scale and a neuropsychological test battery. Data on mortality was obtained from the Dutch municipal register. Associations between age-at-diagnosis and clinical features and mortality risk were examined.

Results: Age-at-diagnosis ranged from 26 to 85 years and established quartiles with mean ages of $52 \pm 6,61 \pm 2,66 \pm 2$, and $74 \pm 3$ years. In the total sample, $44.4 \%$ exceeded an age of 65 years at time of diagnosis. Earlier age-at-diagnosis was associated with more severe behavioral symptoms, while later age-at-diagnosis was associated with more severe memory impairment. Unexpectedly, mortality risk was not associated with age-at-diagnosis.

Conclusion: In bvFTD, symptom profile is associated with age-at-diagnosis. This should be taken into account with regard to diagnostics, patient management, and trial design. Additionally, based on our sample, the prevalence of late-onset bvFTD is higher than generally thought.
\end{abstract}

Keywords: Behavior, cognition, frontotemporal dementia, late-onset, mortality, young-onset

\footnotetext{
${ }^{*}$ Correspondence to: Jay L.P. Fieldhouse, Alzheimer Center Amsterdam, Department of Neurology, Amsterdam UMC, De
}

Boelelaan 1118, $1081 \mathrm{HZ}$ Amsterdam, The Netherlands. Tel.: +31204448527; E-mail: j.fieldhouse@amsterdamumc.nl. 


\section{INTRODUCTION}

Behavioral variant frontotemporal dementia (bvFTD) is known as the most common clinical variant of the frontotemporal dementia (FTD) spectrum, and the second most common cause of young-onset dementia after Alzheimer's disease (AD) [1, 2]. Characterized by severe changes in behavior and personality [3], bvFTD knows a large clinical variability and an age range varying from 21 to 85 years of age at onset [4]. This heterogeneity challenges diagnostics, patient management, and trial cohort design. While the prevalence of FTD is generally considered to be highest within the age categories $45-64$ years [5,6], other population-based studies reported a higher prevalence and incidence of bvFTD in elderly than commonly thought [7-11], suggesting bvFTD is relatively underdiagnosed in the elderly population. This poor recognition might be related to a different symptom presentation in late-onset bvFTD. Indeed, late-onset FTD has shown to present more frequently with memory deficits $[12,13]$, thus reducing the sensitivity of current diagnostic criteria for bvFTD, as these consider a relatively spared memory as a supportive feature [3]. On the other hand, early-onset FTD has been found to be characterized by predominant behavioral disturbances, and very early-onset bvFTD has been described with a prominent neuropsychiatric presentation (e.g., schizophrenia-like psychosis) $[14,15]$. In line with this thought, there is evidence for different atrophy patterns depending on age at onset, regarding more frequent and severe hippocampal sclerosis in elderly bvFTD versus frontotemporal atrophy in younger onset bvFTD $[12,16]$. Also, several studies report that older age at onset is associated with shorter survival in dementia in general, FTD, and bvFTD [17-19], although this may be largely explained by the general notion of decreased life expectancy with aging.

With regard to clinical differences based on age at onset, a few studies have been performed with varying results. Whereas some of these support the concept of early- and late-onset FTD as distinct phenotypes [12, $13,15]$, others did not support this [20], or found partly contradicting results [21]. However, limitations of these studies are either a small sample size, inclusion of language variants of FTD, outdated diagnostic criteria or lack of extensive cognitive testing. Furthermore, biomarkers indicative of AD have not been applied in these studies, thereby risking the erroneous inclusion of AD cases [22]. Lastly, young-onset dementia, including young-onset bvFTD, is generally defined as dementia occurring before the age of 65 years. While this traditional cut-off point is widely used and seems appropriate in other neurodegenerative diseases, it is rather arbitrary and most likely based on sociological grounds [23, 24]. The heterogeneous nature of bvFTD may require a different cut-off point or a less dichotomous perspective.

Determination of potential age-related phenotypes may be essential for diagnostics, appropriate care, and future clinical trial design. Depending on age at onset, subgroups in bvFTD might call for different outcome measures. Therefore, we examined clinical phenotypes of bvFTD on the complete continuum of age, through assessing neuropsychiatric symptoms, cognitive functioning, and survival rates in a biomarker validated cohort with the most recent clinical criteria. Based on previous literature, we hypothesized predominant behavioral disturbances would characterize younger patients with bvFTD and a milder behavioral profile, more profound memory deficits and shorter survival would occur in older patients with bvFTD.

\section{METHODS}

\section{Study population}

All patients with a clinical diagnosis of probable or definite bvFTD were included from the Amsterdam Dementia Cohort $(n=315)$ [25]. In this cohort, patients underwent a standardized dementia screening between September 1998 and October 2019, including neuropsychological assessment, neurological examination, laboratory tests, and/or genetic screening. Clinical diagnosis of bvFTD was established by consensus in a multidisciplinary meeting, and level of certainty was assigned according to the revised international diagnostic criteria (FTDC) [3]. Consequently, cases with frontal and/or anterior temporal atrophy or hypoperfusion on MRI, CT, PET, or SPECT were classified as probable bvFTD. When a known pathogenic mutation was present or histopathological evidence was found at postmortem examination, cases were classified as definite bvFTD. Fifty patients were tested positive on a pathogenic mutation (33 C9orf72, 8 MAPT, 6 GRN, 2 TARDP, 1 CHMP2B) and nineteen patients had histopathological evidence postmortem (17 TDP, 2 FUS). For cases before 2011, fulfillment of FTDC criteria was assigned retrospectively, including biomarker confirmation on neuroimaging, genetics and/or pathology, 
as well as AD markers in cerebrospinal fluid (CSF) (authors initials who have contributed to retrospective assignment: JF, SB, YP, EV). Patients with a diagnosis of possible bvFTD, i.e., behavioral disturbances without confirmation on neuroimaging, genetics, or pathology, were excluded $(n=46)$. CSF was available of 239 patients. Patients with an AD CSF profile were excluded $(n=22)$, i.e., abnormal p-tau/amyloidbeta42 ratio ( $>0.214$ Innotest; $>0.020$ Elecsys) or abnormal amyloid-beta42 $(<813$ Innotest $<1000$ Elecsys) and p-tau (>52 Innotest; >19 Elecsys). MRI Fazekas score was available of 196 patients. Patients with severe cerebrovascular damage were excluded $(n=6)$, i.e., Fazekas score of 3 representing a high burden of white matter hyperintensities. For this study, we investigated cross-sectional baseline data of all patients with available neuropsychiatric and cognitive evaluations.

The study was approved by the Ethics Committee of the Amsterdam UMC (2015.457). All patients provided written informed consent to use their clinical data for research purposes. Sex and level of education of all patients was assessed. Level of education was classified using the Verhage system ranging from 1 (no or little education) to 7 (highest academic degree) [26].

\section{Age at onset}

Age-at-diagnosis was assessed at the standardized dementia screening. Symptom duration was assessed by the number of years of disease related complaints reported by the patients' caregiver. Weighing expert diagnosis over caregivers' perception, age at onset was defined as age-at-diagnosis. Based on characteristics of our study population the sample was divided in quartiles of age-at-diagnosis; very early onset in the first/youngest quartile (Q1), early onset in the second quartile $(\mathrm{Q} 2)$, late onset in the third quartile $(\mathrm{Q} 3)$, and very late onset in the last/eldest quartile $(\mathrm{Q} 4)$.

\section{Neuropsychiatric assessment}

Neuropsychiatric symptoms were assessed with the informant-rated Neuropsychiatric Inventory (NPI) [27, 28] and the Geriatric Depression Scale (GDS) [29]. For the NPI, scores were transformed to severity (frequency x severity, ranging 0-12) and a total neuropsychiatric score (NPI sum of scores, ranging 0-144). Data of the NPI was available of 203 patients (64.4\%) and GDS was available of 200 patients $(63.5 \%)$. For all behavioral variables, higher scores indicate more severe behavioral symptoms.

\section{Neuropsychological testing}

Dementia severity and global cognition were assessed with the Clinical Dementia Rating scale (CDR) [30], the Mini-Mental State Examination (MMSE) [31], and the Frontal Assessment Battery (FAB) [32]. Extensive cognitive assessment was performed using a standardized test battery covering five cognitive domains: memory, attention, executive functioning, language, and visuospatial functioning. The domain memory included the total immediate and delayed recall of the Dutch version of the Rey Auditory Verbal Learning Task and the total recall on Visual Association Test (VAT) [33, 34]. The domain attention included the Trail Making Test part A (TMT-A), the forward condition of digit span, and the word and color subtests of the Stroop test [35-37]. The domain executive functioning included the trail making test part B (TMT-B), the backward condition of digit span, the color-word subtest of the Stroop test and the letter fluency [35-38]. The domain language included the category fluency (animal naming) and the naming condition of the VAT $[33,39]$. Lastly, the domain visuospatial functioning included three subtests of the visual object and space perception battery: number location, dot counting, and fragmented letters [40]. The test scores of pace dependent tests (TMT-A, TMT-B, and Stroop subtests) were not normally distributed, and therefore log-transformed and inverted to ensure lower scores indicated poorer cognitive performance. Raw test scores were converted into z-scores using the mean and standard deviation of our study population. Global cognitive performance was estimated by averaging the z-scores of all tests. Domain z-scores were calculated by averaging the $\mathrm{z}$-scores of all tests within a cognitive domain. Cognitive scores were available of a large majority of patients; memory $(n=261$, $82.9 \%)$, attention $(n=265,84.1 \%)$, executive functioning $(n=262,83.2 \%)$, language $(n=257,81.6 \%)$, visuospatial functioning $(n=200,63.5 \%)$, MMSE $(n=270,85.7 \%)$, and FAB $(n=225,71.4 \%)$. For all cognitive variables, lower scores indicate poorer cognitive functioning.

\section{Mortality}

For all patients, information on all-cause mortality (died yes/no with the date of death) was obtained from the Dutch municipal register. This register was searched on April 6, 2020. Causes of death cannot be determined from this municipal registry. For four cases current status was unknown in the register, but 
Table 1

Characteristics of the total sample and by age quartiles

\begin{tabular}{|c|c|c|c|c|c|}
\hline & $\begin{array}{c}\text { Total } \\
\text { sample }\end{array}$ & $\begin{array}{l}\text { Very early } \\
\text { onset (Q1) }\end{array}$ & $\begin{array}{c}\text { Early } \\
\text { onset (Q2) }\end{array}$ & $\begin{array}{c}\text { Late } \\
\text { onset }(\mathrm{Q} 3)\end{array}$ & $\begin{array}{l}\text { Very late } \\
\text { onset }(\mathrm{Q} 4)\end{array}$ \\
\hline $\mathrm{N}(\%)$ & $315(100)$ & $79(25.1)$ & $81(25.7)$ & $84(26.7)$ & $71(22.5)$ \\
\hline Age-at-diagnosis, $\mathrm{y}$ & $62.9 \pm 8.8$ & $51.8 \pm 6.3$ & $60.5 \pm 1.7$ & $66.4 \pm 1.6$ & $74.0 \pm 3.2$ \\
\hline Age-at-diagnosis range, $y$ & $26-85$ & $26-57$ & $58-63$ & $64-69$ & $70-85$ \\
\hline Symptom duration, $\mathrm{y}$ & $3.6 \pm 3.2$ & $3.4 \pm 2.8$ & $3.2 \pm 3.2$ & $4.1 \pm 3.3$ & $3.7 \pm 3.4$ \\
\hline Sex, $n$ female $(\%)$ & $120(38.1)$ & $33(41.8)^{d}$ & $37(45.7)^{d}$ & $34(40.5)^{d}$ & $16(22.5)^{\mathrm{a} b c}$ \\
\hline Education, Verhage & $4.9 \pm 1.3$ & $5.0 \pm 1.2$ & $4.7 \pm 1.2$ & $4.8 \pm 1.2$ & $5.1 \pm 1.4$ \\
\hline Probable bvFTD, $n(\%)$ & $251(79.7)$ & $55(68.8)$ & $63(75.9)$ & $73(84.9)$ & $66(91.7)$ \\
\hline Definite bvFTD, $n(\%)$ & $64(20.3)$ & $25(31.6)^{c d}$ & $20(24.7)^{d}$ & $13(15.5)^{a}$ & $6(8.5)^{a b}$ \\
\hline Pathogenic mutation, $n(\%)$ & $50(15.9)$ & $20(25.3)^{\mathrm{cd}}$ & $16(19.8)^{d}$ & $10(11.9)^{a}$ & $4(5.6)^{a b}$ \\
\hline Histopathologic evidence, $n(\%)$ & $19(6.0)$ & $6(7.6)$ & $7(8.6)$ & $4(4.8)$ & $2(2.8)$ \\
\hline CDR & $0.8 \pm 0.5$ & $0.9 \pm 0.5$ & $0.9 \pm 0.4$ & $0.8 \pm 0.5$ & $0.8 \pm 0.5$ \\
\hline
\end{tabular}

Data are presented as mean $\pm \mathrm{SD} ; n(\%)$; Q1-Q4, quartiles of age-at-diagnosis; y, years; Symptom duration, presence of disease related complaints reported by caregiver; Education, level of education (Verhage system 0-7); CDR, Clinical Dementia Rating scale (0-3); ${ }^{\text {significantly }}$ different from Q1, ${ }^{\mathrm{b}}$ significantly different from Q2, ${ }^{\mathrm{c}}$ significantly different from Q3, ${ }^{\mathrm{d}}$ significantly different from Q4; $p<0.05$.

data was established by their general practitioners. For one case date of death was unknown, resulting in 1 missing in the mortality data. For survival time, we included all patients and defined follow-up duration as time between date of diagnosis and date of death, or if alive, between date of diagnosis and April 6, 2020.

\section{Data analyses}

All statistical analyses were performed with SPSS version 22 (released 2013, IBM SPSS Statistics for Windows, Armonk, NY, USA). Significance was set at $p$-value $<0.05$ for all analyses. Group differences in characteristics were tested using analysis of variance (ANOVA) or Chi-Square-tests when appropriate. Associations between age-at-diagnosis (independent variable) and behavioral and cognitive scores (NPI, GDS, and neuropsychological z-scores; dependent variables) were assessed using linear regression analyses (adjusted for sex, educational level, and symptom duration). Data are presented as standardized beta coefficients (Beta). A Cox proportional hazard model (adjusted for sex, educational level, and symptom duration) was used to assess the association between age-at-diagnosis as a continuous variable and mortality risk, taking into account time to death. Data is presented as hazard ratio with accompanying 95\% confidence interval (HR (95\% CI)).

\section{RESULTS}

\section{Characteristics}

The total sample consisted of 315 patients, of which 251 fulfilled the criteria of probable bvFTD
(79.7\%) and 64 met the criteria of definite bvFTD (20.3\%) (Table 1). Age-at-diagnosis ranged from 26 to 85 years of age, with a mean age of $62.9 \pm 8.8$. Division of the sample in quartiles established four age groups with a mean age of $51.8 \pm 6.3$ (very early onset, Q1), $60.5 \pm 1.7$ (early onset, Q2), $66.4 \pm 1.6$ (late onset, Q3), and 74.0 \pm 3.2 (very late onset, Q4). When the sample was divided in the traditional cutoff at 65 years of age, $55.6 \%$ was younger than 65 years $(n=175)$ and $44.4 \%$ was 65 years or older $(n=140)$. The total sample showed a small predominance of males $(61.9 \%)$. The very late onset subgroup comprised of relatively more males than lower age quartiles ( $p=0.019$; Q4-Q1, Q4-Q2, Q4-Q3 all $p<0.05)$. Lower age quartiles comprised relatively more pathogenic mutation carriers and therefore more definite bvFTD cases than higher age quartiles $(p=0.005 ; p=0.002$ respectively; $\mathrm{Q} 1-\mathrm{Q} 3, \mathrm{Q} 1-\mathrm{Q} 4$, Q2-Q4 all $p<0.05)$.

\section{Clinical features}

Linear regression analyses showed age-at-diagnosis was associated with several behavioral symptoms and impaired memory performance. Ageat-diagnosis was negatively associated with the severity of euphoria (NPI; Beta $-0.167, p=0.021$ ), the severity of apathy (NPI; Beta $-0.168, p=0.020$ ), and the severity of depressive symptoms (GDS; Beta $-0.277, p=0.000$ ), showing that younger patients present with more severe euphoric, apathetic, and depressive symptoms than older patients with bvFTD. For visualization, distributions of neuropsychiatric symptoms of age quartiles are shown in Fig. 1. Looking into age quartiles, more 

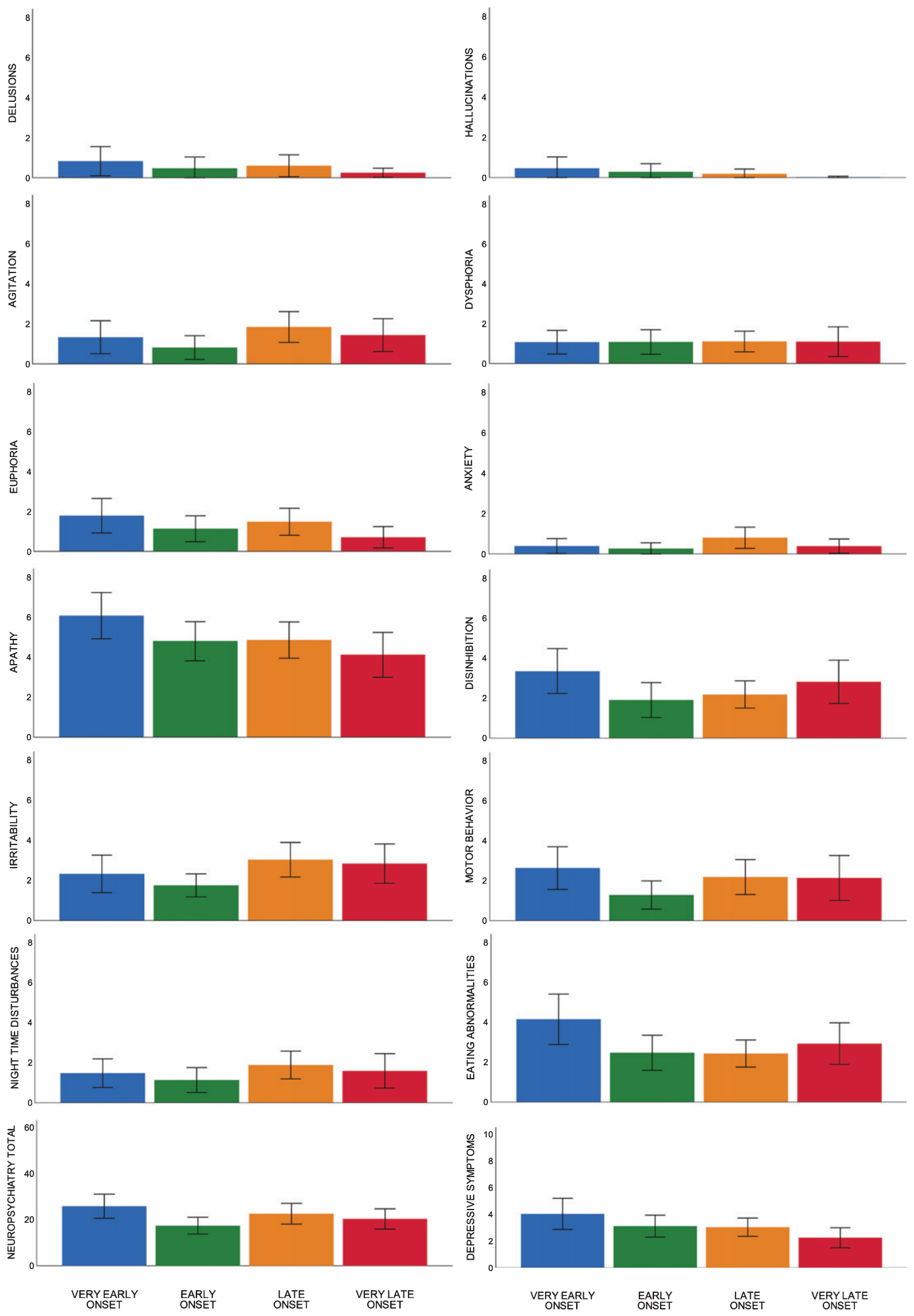

Fig. 1. Mean scores of neuropsychiatric symptoms per age quartile. 


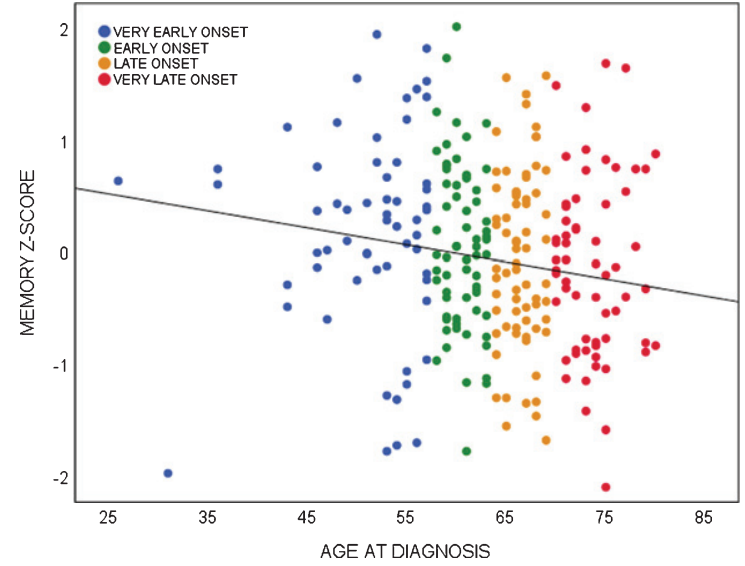

Fig. 2. Association between memory performance and age-atdiagnosis in bvFTD.

severe behavioral deficits seem to be attributed to the youngest subgroup. As for cognition, age-atdiagnosis was negatively associated with memory performance (Beta $-0.153, p=0.021$ ), showing older patients present with more severe memory deficits than younger patients with bvFTD. Divided in age quartiles, the association between memory performance and age-at-diagnosis is shown in Fig. 2.

\section{Mortality}

A total of 158 patients were deceased at time of analyses (50.2\%). For deceased patients, survival time from date of diagnosis to date of death ranged from 0 to 17 years with a mean survival time of $4.2 \pm 3.0$ years. Cox regression analysis showed there was no association between age-at-diagnosis and mortality (HR 1.02 (95\% CI 0.995-1.042, $p=0.118$ ), meaning there is no increased risk of mortality associated with age-at-diagnosis. Furthermore, mortality risk did not differ between age quartiles (log-rank test, $p=0.155$ ). Survival curves of age quartiles are shown in Fig. 3.

\section{DISCUSSION}

The association between clinical phenotype and age-at-diagnosis was investigated in our cohort of biomarker confirmed probable and definite bvFTD patients of a wide age range. Our main finding is that patients with earlier age-at-diagnosis present with more severe behavioral symptoms, while patients with later age-at-diagnosis present with more profound memory deficits. In more detail, we found that

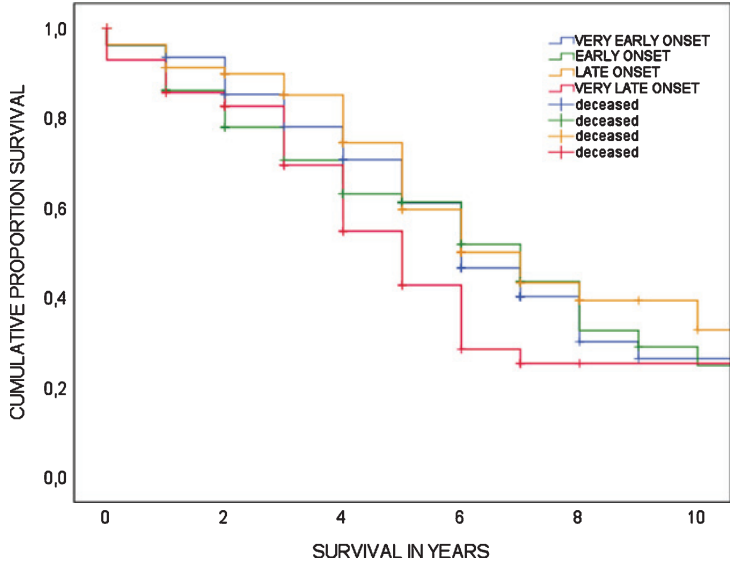

Fig. 3. Survival in bvFTD, showing Kaplan-Meier curves according to age quartiles; log-rank test is $p=0.155$.

earlier age-at-diagnosis was associated with more severe symptoms of euphoria, apathy and depression than later age-at-diagnosis. There was no increased risk of mortality with increasing age-at-diagnosis. Also, division in the traditional cut-off at 65 years of age showed almost half of the sample (44.4\%) comprised of late-onset bvFTD.

As for the behavioral profile, our results confirm previous smaller studies stating predominant and more severe behavioral symptoms in early-onset FTD compared to late-onset FTD [12, 15, 21], in particular regarding apathy [21]. In contrast, one study $(n=35$ FTD $)$ stated apathy was more frequent in late-onset than early-onset [13], and another study ( $n=134$ bvFTD) found no differences in the behavioral profiles by age at onset [20]. However, these studies used outdated diagnostic criteria of bvFTD, and comparisons among studies that use different diagnostic criteria presumed a low validity for specifically elderly bvFTD [7]. Looking into the actual differences we found in apathy scores, one could argue the relative difference between the age subgroups seem trivial. Yet, among neuropsychiatric symptoms in bvFTD, especially apathy is associated with functional disability [41], caregiver distress [42], and more rapid institutionalization [43]. Since the severity of apathy strongly affects patient and caregiver burden, these subtle yet significant differences may have important clinical relevance in early-onset bvFTD. Furthermore, the finding that patients with earlier age at onset presented with more severe euphoric and depressive symptoms than later age at onset might sound contradicting. Yet, looking into the content of the NPI, the items on euphoria 
rather encompass abundant and inappropriate behavior, e.g., insensible jokes or childish games, which might not be specifically related to mood. Involving a core clinical symptom of the disease, this inappropriate behavior is particularly relevant in bvFTD and may represent its main aberrant behavior.

Our finding that later age-at-diagnosis of bvFTD was associated with more severe memory impairment confirms previous literature $[12,13]$. Although one study reported more profound memory impairment in early versus late-onset FTD, this was not the case in subanalyses of its behavioral variant [21]. Underlying memory dysfunction, late-onset bvFTD may follow a different pathological pathway. In fact, late-onset FTD is characterized by more severe hippocampal sclerosis versus less cortical frontotemporal atrophy, than early-onset FTD $[12,15,16]$. These structural characteristics may be related to distinct atrophy patterns following frontal/frontotemporal salience networks versus semantic appraisal or subcortical networks [44]. Moreover, age-related factors as comorbidity may play a part in older patients with bvFTD. Compared to early-onset, late-onset FTD has been associated with more comorbid pathologic changes and higher rates of mixed pathology, including $\mathrm{AD}$, cerebral amyloid angiopathy, vascular brain injury, and hippocampal sclerosis [6]. These nonFTD changes become more prevalent with age [45, 46] and may negatively affect memory function. However, by excluding cases with AD positive CSF and cases with severe cerebrovascular damage, we diminished the possibility of comorbid AD and cerebrovascular disease.

We found no association between mortality risk and age-at-diagnosis, while several studies reported that older age at onset was associated with shorter survival in FTD [17-19]. Because life expectancy generally decreases with age, one interpretation could be that the relative shortening of life in younger patients with bvFTD is larger. Indeed, young-onset and late-onset FTD has shown a remarkably shorter survival time compared to the general Dutch population [19]. Also, the effect of age on survival may differ in patients with and without genetic mutations $[17,18]$, as age at onset, progression rate, and age at death in genetic FTD showed to be strongly influenced by the specific mutation and family membership [47, 48]. Since we have not systematically performed genetic screening in our full cohort, we were not able to account for the effects of pathogenic mutations among the separate age groups. As clinical profile may be affected by the underlying pathogenic mutation and/or pathology, this requires further study.

The symptom profile of predominant behavior disturbances in earlier-onset bvFTD and more profound memory impairment in later-onset bvFTD might contribute to the current challenge faced in bvFTD diagnostics. While behavioral symptoms in younger patients may explain the foremost differential diagnosis with primary psychiatric disorders, memory deficits in older patients call for differentiation from AD. Awareness of these age-related phenotypes could improve diagnostics considerably. Furthermore, in this study almost half of the sample $(44.4 \%)$ exceeded an age of 65 years at time of diagnosis, surpassing the estimated prevalence of LO-FTD between $25-30 \%$ in literature $[5,6]$, but confirming studies stating onset after 65 years of age is more common than previously thought $[8,20,21]$. While late-onset FTD knows more frequent misdiagnoses and is most likely mistaken for $\mathrm{AD}$, we reduced this probability by exclusion of cases with possible bvFTD or AD biomarkers [6, 49]. Since the current diagnostic bvFTD criteria state a relatively sparing of memory as a supportive feature [3], underrepresentation of bvFTD in the elderly population remains a threat. Because a correct diagnosis is essential to accurate clinical practice and research, this should be addressed in novel diagnostic guidelines and considered in future cohort design.

There are a few limitations in this study. Firstly, age at onset was defined with age-at-diagnosis, which does not equal actual disease onset. Particularly in bvFTD, disease onset is hard to determine as symptoms may present as subtle and insidious changes in behavior, sensitive to subjectivity. In this light, we chose a more objective construct based on expert diagnosis over caregivers' perception. Secondly, we included bvFTD patients from a standardized dementia screening with clinical assessment of general dementia instruments, such as the NPI and GDS. Considering the challenge to capture bvFTD in traditional dementia work-ups, usage of bvFTD specific measures and questionnaires would be preferred (e.g., FTLD adjusted CDR [50] and Cambridge Behavioral Inventory [51]). However, in this clinical cohort design, we were able to collect data from a large group of patients, during an extended period of time, while generally covering important clinical features. Lastly, missing values were relatively high in the behavioral measures (NPI 35.6\%, GDS 36.5\%). Nevertheless, these numbers of missing NPI or GDS were equally distributed across the age spectrum. 
As far as we are aware, this is the first and largest study on age-related phenotypes of bvFTD, with updated clinical criteria and biomarker validation. By excluding possible bvFTD cases lacking confirmation on neuroimaging (frontotemporal atrophy/hypometabolism), as well as cases with positive AD biomarkers, most common misdiagnoses of primary psychiatric disorders and $\mathrm{AD}$ were reduced. Other strengths are the examination of bvFTD onset in a wide age range, the use of an extensive cognitive test battery and up-to-date mortality data.

In conclusion, symptom profile is associated with age-at-diagnosis in bvFTD. The subtle yet significant differences in behavior and cognition may influence diagnostics and should be considered in future clinical trial design. Furthermore, our findings suggest that late disease onset and memory deficits are more frequent in bvFTD than generally thought. Future studies are needed to further examine age-related differences in bvFTD. Inclusion of longitudinal behavioral and cognitive assessment, systematic genetic screening, social cognitive evaluation, and imaging/fluid biomarkers may contribute to current findings and provide better understanding of the heterogeneous nature of bvFTD.

\section{ACKNOWLEDGMENTS}

Research of Alzheimer Center Amsterdam is part of the neurodegeneration research program of Amsterdam Neuroscience. Alzheimer Center Amsterdam is supported by Stichting Alzheimer Nederland and Stichting VUmc fonds. Yolande A.L. Pijnenburg received funding from Stichting Dioraphte. We thank Stichting Diorapthe for their support.

Authors' disclosures available online (https:// www.j-alz.com/manuscript-disclosures/21-0179r1).

\section{REFERENCES}

[1] Neary D, Snowden JS, Gustafson L, Passant U, Stuss D, Black S, Freedman M, Kertesz A, Robert PH, Albert M, Boone K, Miller BL, Cummings J, Benson DF (1998) Frontotemporal lobar degeneration: A consensus on clinical diagnostic criteria. Neurology 51, 1546-1554.

[2] Hogan DB, Jetté N, Fiest KM, Roberts JI, Pearson D, Smith EE, Roach P, Kirk A, Pringsheim T, Maxwell CJ (2016) The prevalence and incidence of frontotemporal dementia: A systematic review. Can J Neurol Sci 43, S96-S109.

[3] Rascovsky K, Hodges JR, Knopman D, Mendez MF, Kramer JH, Neuhaus J, van Swieten JC, Seelaar H, Dopper EG, Onyike CU, Hillis AE, Josephs KA, Boeve BF, Kertesz A, Seeley WW, Rankin KP, Johnson JK, Gorno-Tempini ML, Rosen H, Prioleau-Latham CE, Lee A, Kipps CM, Lillo
P, Piguet O, Rohrer JD, Rossor MN, Warren JD, Fox NC, Galasko D, Salmon DP, Black SE, Mesulam M, Weintraub S, Dickerson BC, Diehl-Schmid J, Pasquier F, Deramecourt V, Lebert F, Pijnenburg Y, Chow TW, Manes F, Grafman J, Cappa SF, Freedman M, Grossman M, Miller BL (2011) Sensitivity of revised diagnostic criteria for the behavioural variant of frontotemporal dementia. Brain 134, 24562477.

[4] Neary D, Snowden J, Mann D (2005) Frontotemporal dementia. Lancet Neurol 4, 771-780.

[5] Knopman DS, Roberts RO (2011) Estimating the number of persons with frontotemporal lobar degeneration in the US population. J Mol Neurosci 45, 330-335.

[6] Seo SW, Thibodeau M-P, Perry DC, Hua A, Sidhu M, Sible I, Vargas JNS, Gaus SE, Rabinovici GD, Rankin KD, Boxer AL, Kramer JH, Rosen HJ, Gorno-Tempini ML, Grinberg LT, Huang EJ, DeArmond SJ, Trojanowski JQ, Miller BL, Seeley WW (2018) Early vs late age at onset frontotemporal dementia and frontotemporal lobar degeneration. Neurology 90, e1047-e1056.

[7] Gislason TB, Östling S, Börjesson-Hanson A, Sjögren M, Simoni M, Pantoni L, Skoog I (2015) Effect of diagnostic criteria on prevalence of frontotemporal dementia in the elderly. Alzheimers Dement 11, 425-433.

[8] Gislason TB, Sjögren M, Larsson L, Skoog I (2003) The prevalence of frontal variant frontotemporal dementia and the frontal lobe syndrome in a population based sample of 85 year olds. J Neurol Neurosurg Psychiatry 74, 867-871.

[9] Garre-Olmo J, Genis Batlle D, del Mar Fernandez M, Marquez Daniel F, de Eugenio Huelamo R, Casadevall T, Turbau Recio J, Turon Estrada A, Lopez-Pousa S (2010) Incidence and subtypes of early-onset dementia in a geographically defined general population. Neurology 75, 1249-1255.

[10] Nilsson C, Landqvist Waldö M, Nilsson K, Santillo A, Vestberg S (2014) Age-related incidence and family history in frontotemporal dementia: Data from the Swedish Dementia Registry. PloS One 9, e94901-e94901.

[11] Leroy M, Bertoux M, Skrobala E, Mode E, Adnet-Bonte C, Le Ber I, Bombois S, Cassagnaud P, Chen Y, Deramecourt V, Lebert F, Mackowiak MA, Sillaire AR, Wathelet M, Pasquier F, Lebouvier T (2021) Characteristics and progression of patients with frontotemporal dementia in a regional memory clinic network. Alzheimers Res Ther 13, 19.

[12] Baborie A, Griffiths TD, Jaros E, Momeni P, McKeith IG, Burn DJ, Keir G, Larner AJ, Mann DM, Perry R (2012) Frontotemporal dementia in elderly individuals. Arch Neurol 69, 1052-1060.

[13] Shinagawa S, Toyota Y, Ishikawa T, Fukuhara R, Hokoishi K, Komori K, Tanimukai S, Ikeda M (2008) Cognitive function and psychiatric symptoms in early- and late-onset frontotemporal dementia. Dement Geriatr Cogn Disord 25, 439-444.

[14] Velakoulis D, Walterfang M, Mocellin R, Pantelis C, McLean C (2009) Frontotemporal dementia presenting as schizophrenia-like psychosis in young people: Clinicopathological series and review of cases. $\mathrm{Br} J$ Psychiatry 194, 298-305.

[15] Passant U, Rosen I, Gustafson L, Englund E (2005) The heterogeneity of frontotemporal dementia with regard to initial symptoms, qEEG and neuropathology. Int $J$ Geriatr Psychiatry 20, 983-988.

[16] Baborie A, Griffiths TD, Jaros E, McKeith IG, Burn DJ, Richardson A, Ferrari R, Moreno J, Momeni P, Duplessis D, Pal P, Rollinson S, Pickering-Brown S, Thompson JC, Neary D, Snowden JS, Perry R, Mann DMA (2011) 
Pathological correlates of frontotemporal lobar degeneration in the elderly. Acta Neuropathol 121, 365-371.

[17] Cosseddu M, Benussi A, Gazzina S, Turrone R, Archetti S, Bonomi E, Biasiotto G, Zanella I, Ferrari R, Cotelli MS, Alberici A, Padovani A, Borroni B (2018) Mendelian forms of disease and age at onset affect survival in frontotemporal dementia. Amyotroph Lateral Scler Frontotemporal Degener 19, 87-92.

[18] Agarwal S, Ahmed RM, D'Mello M, Foxe D, Kaizik C, Kiernan MC, Halliday GM, Piguet O, Hodges JR (2019) Predictors of survival and progression in behavioural variant frontotemporal dementia. Eur J Neurol 26, 774-779.

[19] Rhodius-Meester HFM, Tijms BM, Lemstra AW, Prins ND, Pijnenburg YAL, Bouwman F, Scheltens P, van der Flier WM (2019) Survival in memory clinic cohort is short, even in young-onset dementia. J Neurol Neurosurg Psychiatry 90, 726-728.

[20] Borroni B, Agosti C, Bellelli G, Padovani A (2008) Is earlyonset clinically different from late-onset frontotemporal dementia? Eur J Neurol 15, 1412-1415.

[21] Ye BS, Choi SH, Han S-H, Kim S, Yang D-W, Park KH, Han HJ, Youn YC, Choi B-O, Kim SH, Woo S-y, Na DL, Kim E-J (2015) Clinical and neuropsychological comparisons of early-onset versus late-onset frontotemporal dementia: A CREDOS-FTD study. J Alzheimers Dis 45, 599-608.

[22] Ossenkoppele R, Pijnenburg YA, Perry DC, Cohn-Sheehy BI, Scheltens NM, Vogel JW, Kramer JH, van der Vlies AE, La Joie R, Rosen HJ, van der Flier WM, Grinberg LT, Rozemuller AJ, Huang EJ, van Berckel BN, Miller BL, Barkhof F, Jagust WJ, Scheltens P, Seeley WW, Rabinovici GD (2015) The behavioural/dysexecutive variant of Alzheimer's disease: Clinical, neuroimaging and pathological features. Brain 138, 2732-2749.

[23] Vieira RT, Caixeta L, Machado S, Silva AC, Nardi AE, Arias-Carrión O, Carta MG (2013) Epidemiology of earlyonset dementia: A review of the literature. Clin Pract Epidemiol Ment Health 9, 88-95.

[24] Rossor MN, Fox NC, Mummery CJ, Schott JM, Warren JD (2010) The diagnosis of young-onset dementia. Lancet Neurol 9, 793-806.

[25] van der Flier WM, Scheltens P (2018) Amsterdam Dementia Cohort: Performing research to optimize care. J Alzheimers Dis 62, 1091-1111.

[26] Verhage F (1965) Intelligence and age in a Dutch sample. Hum Dev 8, 238-245.

[27] Cummings JL, Mega M, Gray K, Rosenberg-Thompson S, Carusi DA, Gornbein J (1994) The Neuropsychiatric Inventory: Comprehensive assessment of psychopathology in dementia. Neurology 44, 2308-2308.

[28] Cummings JL (1997) The Neuropsychiatric Inventory: Assessing psychopathology in dementia patients. Neurology 48, S10-16.

[29] Sheikh JI, Yesavage JA (1986) Geriatric Depression Scale (GDS): Recent evidence and development of a shorter version. Haworth Press, US, pp. 165-173.

[30] Morris JC (1993) The Clinical Dementia Rating (CDR): Current version and scoring rules. Neurology 43, 24122414.

[31] Folstein MF, Folstein SE, McHugh PR (1975) "Minimental state". A practical method for grading the cognitive state of patients for the clinician. J Psychiatr Res 12, 189-198.

[32] Dubois B, Slachevsky A, Litvan I, Pillon B (2000) The FAB: A Frontal Assessment Battery at bedside. Neurology 55, 1621-1626.
[33] Lindeboom J, Schmand B, Tulner L, Walstra G, Jonker C (2002) Visual association test to detect early dementia of the Alzheimer type. J Neurol Neurosurg Psychiatry 73, 126-133.

[34] Rey A (1964) L'examen clinique en psychologie, Presses universitaires de France.

[35] Reitan RM (1955) The relation of the trail making test to organic brain damage. J Consult Psychol 19, 393-394.

[36] Wechsler D, Psychological C (1997) WAIS-III : Administration and scoring manual : Wechsler Adult Intelligence Scale. Psychological Corporation, San Antonio, TX.

[37] Stroop JR (1935) Studies of interference in serial verbal reactions. J Exp Psychol 18, 643.

[38] Hughes CP, Berg L, Danziger W, Coben LA, Martin RL (1982) A new clinical scale for the staging of dementia. $\mathrm{Br}$ J Psychiatry 140, 566-572.

[39] Benton AL (1968) Differential behavioral effects in frontal lobe disease. Neuropsychologia 6, 53-60.

[40] Warrington EK, James M, Thames Valley Test C (1991) The visual object and space perception battery, Thames Valley Test Company, Bury St. Edmunds.

[41] Yassuda MS, Lima da Silva TB, O'Connor CM, Mekala S, Alladi S, Bahia VS, Amaral-Carvalho V, Guimaraes HC, Caramelli P, Balthazar MLF, Damasceno B, Brucki SMD, Nitrini R, Hodges JR, Piguet O, Mioshi E (2018) Apathy and functional disability in behavioral variant frontotemporal dementia. Neurol Clin Pract 8, 120-128.

[42] Merrilees J, Dowling GA, Hubbard E, Mastick J, Ketelle R, Miller BL (2013) Characterization of apathy in persons with frontotemporal dementia and the impact on family caregivers. Alzheimer Dis Assoc Disord 27, 62-67.

[43] Bakker C, de Vugt ME, van Vliet D, Verhey FR, Pijnenburg YA, Vernooij-Dassen MJ, Koopmans RT (2013) Predictors of the time to institutionalization in young- versus late-onset dementia: Results from the Needs in Young Onset Dementia (NeedYD) study. J Am Med Dir Assoc 14, 248-253.

[44] Ranasinghe KG, Rankin KP, Pressman PS, Perry DC, Lobach IV, Seeley WW, Coppola G, Karydas AM, Grinberg LT, Shany-Ur T, Lee SE, Rabinovici GD, Rosen HJ, GornoTempini ML, Boxer AL, Miller ZA, Chiong W, DeMay M, Kramer JH, Possin KL, Sturm VE, Bettcher BM, Neylan M, Zackey DD, Nguyen LA, Ketelle R, Block N, Wu TQ, Dallich A, Russek N, Caplan A, Geschwind DH, Vossel KA, Miller BL (2016) Distinct subtypes of behavioral variant frontotemporal dementia based on patterns of network degeneration. JAMA Neurol 73, 1078-1088.

[45] Price JL, Davis PB, Morris JC, White DL (1991) The distribution of tangles, plaques and related immunohistochemical markers in healthy aging and Alzheimer's disease. Neurobiol Aging 12, 295-312.

[46] Thal DR, Grinberg LT, Attems J (2012) Vascular dementia: Different forms of vessel disorders contribute to the development of dementia in the elderly brain. Exp Gerontol 47, 816-824.

[47] Moore KM, Nicholas J, Grossman M, McMillan CT, Irwin DJ, Massimo L, Van Deerlin VM, Warren JD, Fox NC, Rossor MN, Mead S, Bocchetta M, Boeve BF, Knopman DS, Graff-Radford NR, Forsberg LK, Rademakers R, Wszolek ZK, van Swieten JC, Jiskoot LC, Meeter LH, Dopper EG, Papma JM, Snowden JS, Saxon J, Jones M, PickeringBrown S, Le Ber I, Camuzat A, Brice A, Caroppo P, Ghidoni R, Pievani M, Benussi L, Binetti G, Dickerson BC, Lucente D, Krivensky S, Graff C, Öijerstedt L, Fallström M, Thonberg H, Ghoshal N, Morris JC, Borroni B, Benussi A, Padovani A, Galimberti D, Scarpini E, Fumagalli GG, 
Mackenzie IR, Hsiung GR, Sengdy P, Boxer AL, Rosen H, Taylor JB, Synofzik M, Wilke C, Sulzer P, Hodges JR, Halliday G, Kwok J, Sanchez-Valle R, Lladó A, Borrego-Ecija S, Santana I, Almeida MR, Tábuas-Pereira M, Moreno F, Barandiaran M, Indakoetxea B, Levin J, Danek A, Rowe JB, Cope TE, Otto M, Anderl-Straub S, de Mendonça A, Maruta C, Masellis M, Black SE, Couratier P, Lautrette G, Huey ED, Sorbi S, Nacmias B, Laforce R, Jr., Tremblay ML, Vandenberghe R, Damme PV, Rogalski EJ, Weintraub S, Gerhard A, Onyike CU, Ducharme S, Papageorgiou SG, Ng ASL, Brodtmann A, Finger E, Guerreiro R, Bras J, Rohrer JD (2020) Age at symptom onset and death and disease duration in genetic frontotemporal dementia: An international retrospective cohort study. Lancet Neurol 19, 145-156.

[48] Khan BK, Yokoyama JS, Takada LT, Sha SJ, Rutherford NJ, Fong JC, Karydas AM, Wu T, Ketelle RS, Baker MC, Hernandez MD, Coppola G, Geschwind DH, Rademakers R, Lee SE, Rosen HJ, Rabinovici GD, Seeley WW, Rankin
KP, Boxer AL, Miller BL (2012) Atypical, slowly progressive behavioural variant frontotemporal dementia associated with C9ORF72 hexanucleotide expansion. J Neurol Neurosurg Psychiatry 83, 358-364.

[49] Marelli C, Gutierrez L-A, Menjot de Champfleur N, Charroud C, De Verbizier D, Touchon J, Douillet P, Berr C, Lehmann S, Gabelle A (2015) Late-onset behavioral variant of frontotemporal lobar degenerationversus Alzheimer's disease: Interest of cerebrospinal fluidbiomarkerratios. Alzheimers Dement 1, 371-379.

[50] Mioshi E, Flanagan E, Knopman D (2017) Detecting clinical change with the CDR-FTLD: Differences between FTLD and AD dementia. Int $J$ Geriatr Psychiatry 32, 977-982.

[51] Nagahama Y, Okina T, Suzuki N, Matsuda M (2006) The Cambridge Behavioral Inventory: Validation and application in a memory clinic. J Geriatr Psychiatry Neurol 19, 220-225. 